\title{
An unusual case of large symptomatic Brunner's gland adenoma: Endoscopic ultrasound imaging
}

\author{
Melissa A. Martinez, ${ }^{1} \underline{\text { Nicholas J. Zyromski }}^{2,3}$ and Leticia P. Luz ${ }^{1,4}$ \\ ${ }^{1}$ Department of Gastroenterology and Hepatology, Indiana University School of Medicine, Indianapolis, IN, USA \\ ${ }^{2}$ Department of General Surgery, Indiana University School of Medicine, Indianapolis, IN, USA \\ ${ }^{3}$ Department of General Surgery, Roudebush VA Medical Center, Indianapolis, IN, USA \\ ${ }^{4}$ Division of Gastroenterology and Hepatology, Roudebush VA Medical Center, Indianapolis, IN, USA
}

Address for correspondence Dr. Leticia P. Luz, E-mail: moc.liamtoh@zulaicitel

Received 2014 Aug 31; Accepted 2014 Oct 7.

Copyright : (C) Endoscopic Ultrasound

This is an open access article distributed under the terms of the Creative Commons Attribution-NonCommercialShareAlike 3.0 License, which allows others to remix, tweak, and build upon the work non-commercially, as long as the author is credited and the new creations are licensed under the identical terms.

A 60-year-old man presented with intermittent epigastric discomfort and postprandial vomiting. Physical exam and laboratory data were unremarkable. Computerized tomography of the abdomen [Figure 1] showed a $3.4 \mathrm{~cm} \times 2.1 \mathrm{~cm}$ soft tissue mass in the duodenal bulb. Upper esophagogastroduodenoscopy (EGD) showed a medium-sized subepithelial mass in the duodenal apex [Figure 2]; pinch biopsies were unrevealing. Endoscopic ultrasound (EUS) showed a $27 \mathrm{~mm} \times 16 \mathrm{~mm}$ isoechoic lesion originating from the deep mucosa and sub-mucosa without invasion to adjacent structures [Figure 3]; fine-needle aspiration (FNA): nondiagnostic. Follow-up EUS 2 years later revealed interval growth of the mass to $30 \mathrm{~mm} \times 40 \mathrm{~mm}$ and new cystic changes [Figure 4]; repeat FNA with atypical cells. Due to the increase in lesion size, presence of atypia on cytology and persistence of symptoms, surgical resection was performed [Figure 5]. Surgical pathology showed Hyperplastic Brunner's glands (BG) with lymphoid aggregates consistent with BG adenoma (BGA) [ Figure 6].

Brunner's glands are submucosal mucin-secreting glands predominantly located in the proximal duodenum. A BGA is a benign tumor arising from BG with an estimated incidence of $0.008 \%$. It usually presents in the fifth to sixth decade of life and involves the posterior wall of the proximal duodenum. Its pathogenesis is thought to be related to acid hypersecretion.[1, $\underline{2}, \underline{3}]$ Patients can be asymptomatic (11\%), or more frequently have vague upper gastrointestinal symptoms. Clinical presentations may include obstructive symptoms, pancreatitis, and upper gastrointestinal bleeding. $[\underline{2}, 4]$ The diagnosis of BGA can be difficult, it can be diagnosed by EGD; However, as BG proliferations may be covered with normal mucosa, pinch biopsies might be negative. Radiological findings are often nonspecific.[ㅍ] EUS can be useful to diagnose BGA; The features include: Involvement of the mucosa and submucosal layers; variable echogenicity (mixed to hypoechoic); and multiple cystic changes within the tumor.[르, $\underline{3}$ ] Resection of an asymptomatic BGA is controversial. Traditionally, symptomatic BGA has been removed surgically. Endoscopic resection can be considered in smaller or pedunculated lesions in which EUS confirms only submucosal involvement. No recurrence has been reported after resection.[르, $\underline{]}$

\section{Footnotes}

Source of Support: Nil.

Conflicts of Interest: None declared. 


\section{REFERENCES}

1. Rocco A, Borriello P, Compare D, et al. Large Brunner's gland adenoma: Case report and literature review. World J Gastroenterol. 2006;12:1966-8. [PMCID: PMC4087528] [PubMed: 16610009]

2. Gao YP, Zhu JS, Zheng WJ. Brunner's gland adenoma of duodenum: A case report and literature review. World J Gastroenterol. 2004;10:2616-7. [PMCID: PMC4572179] [PubMed: 15300922]

3. Ohba R, Otaka M, Jin M, et al. Large Brunner's gland hyperplasia treated with modified endoscopic submucosal dissection. Dig Dis Sci. 2007;52:170-2. [PubMed: 17171443]

4. Babich JP, Klein J, Friedel DM. Endoscopic removal of a brunneroma with EUS guidance. South Med J. 2010;103:250-2. [PubMed: 20134393]

\section{Figures and Tables}

\section{Figure 1}

\section{2}

Computerized tomography abdomen: Soft tissue mass in the duodenal bulb

\section{Figure 2}

Esophagogastroduodenoscopy: Subepithelial mass in the duodenal apex

Figure 3

\section{?}

Radial endoscopic ultrasound: Isoechoic lesion originating from the deep mucosa and sub-mucosa without invasion to adjacent structures

\section{Figure 4}

\section{2}

Repeat radial endoscopic ultrasound exam (2 years later): Growth of the lesion, with new cystic changes

\section{Figure 5}

Surgical pathology specimen

\section{Figure 6}

\section{2}

Hyperplastic Brunner's glands (BG) with lymphoid aggregates consistent with BG adenoma (H and E) 
An unusual case of large symptomatic Brunner's gland adenoma: Endoscopic ultrasound imaging

Articles from Endoscopic Ultrasound are provided here courtesy of Medknow Publications

An unusual case of large symptomatic Brunner's gland adenoma Endoscopic ultrasound imaging.htm[6/28/2016 2:11:55 PM] 